\title{
11_216_OA_Copyedited
}

\section{Biliary stenting versus surgical bypass for palliation of periampullary malignancy}

\section{Mehrdad Nikfarjam ${ }^{1, *}$, Andrew K. Hadj ${ }^{1}$, Vijayaragavan Muralidharan ${ }^{1}$, Niall Tebbutt $^{2}$, Michael A. Fink ${ }^{1}$, Robert M. Jones ${ }^{1}$, Graham Starkey ${ }^{1}$, Rhys B. Vaughan ${ }^{3}$, Alexander W. Marshall ${ }^{3}$ and Christopher Christophi ${ }^{1}$}

${ }^{1}$ University of Melbourne Department of Surgery and Departments of Oncology ${ }^{2}$ and Gastroenterology ${ }^{3}$, Austin Health, Heidelberg, Victoria, Australia

Correspondence to : Dr Mehrdad Nikfarjam, University Department of Surgery, Austin Health, LTB 8, Studley Road, Heidelberg, Melbourne, Victoria 3084, Australia. e-mail: mehrdad.nikfarjam@gmail.com

\begin{abstract}
Background Patients with periampullary cancers may not be suitable for curative resection due to locally advanced disease, metastases, or poor health. Biliary stenting and surgical bypass are utilized for symptom control, but the true benefit of one technique over the other is not clear.

Methods A retrospective analysis of case records was undertaken of patients with periampullary (pancreatic head/uncinate process, distal bile duct, and ampulla of Vater and surrounding duodenum) malignancy treated between June 2004 and June 2010 in a tertiary center by palliative biliary stenting or palliative surgical bypass.

Results Of 69 patients included in the analysis, combined biliary and gastric bypass was performed on 28, while 41 underwent biliary stent (metallic, $n=39$ ) insertion. Patients undergoing stenting were significantly older and less likely to be offered chemotherapy than those from the surgical bypass group. Overall, there were significantly more complications in the stent insertion group (85\%) than the surgical bypass group (36\%) ( $p=0.003)$. The stent group required significantly more subsequent procedures than the surgical bypass group. Metal stent obstruction occurred in 16 of 39 (41\%) patients, with a median stent patency of 224 days. The overall median survival of patients in this study was 7 months with no significant difference between the groups $(p=0.992)$. The presence of metastases at presentation was the only independent factor associated with decreased survival.
\end{abstract}


Conclusion There was no survival difference between stenting versus surgical bypass for palliation of periampullary cancer. There was however a high rate of stent occlusion and need for repeat procedures in patients treated by metal stenting, suggesting that stenting may be best suited to patients predicted as having the shortest survival.

Keywords Biliary stent; periampullary tumor; biliary bypass surgery; pancreatic cancer; palliation; metal stent; patency; cholangitis; survival

\section{Introduction}

Periampullary malignancy, which includes cancer of the head of pancreas, distal bile duct, and ampulla of Vater and the surrounding duodenum, generally has a poor prognosis [1]. In the majority of patients at the time of diagnosis the disease is either too locally advanced for potential curative pancreaticoduodenectomy or there is an evidence of metastatic disease. In addition, the high morbidity associated with pancreaticoduodenectomy may preclude it being offered to certain patients with significant medical comorbidities.

The optimal form of palliative therapy for periampullary cancer is controversial. Most would claim that for patients being considered for curative resection, who are found to have metastases or deemed inoperable at the time of surgery, surgical biliary and gastric bypass may provide long-lasting palliation [2]. In some centers, surgical biliary and gastric bypass is routinely performed by laparoscopic means with documented faster recovery than open surgical techniques $[3,4]$.

The superiority of surgical bypass compared to endoscopic palliation of periampullary malignancy, particularly in metastatic disease, is undetermined [2, 4-9]. There are also very few modern series that document the success of one procedure over another to provide guidelines as to the most appropriate technique in certain situations.

In this study we compared the outcomes of a contemporary series of patients with periampullary cancer that were palliated by surgical bypass to those treated by endoscopic stenting. Differences in patient characteristics, selection criteria, complications, and factors affecting overall survival were determined. In patients with metal biliary stents for palliation, various factors potentially influencing stent patency were assessed.

\section{Methods}

\section{Patient population}

Patients treated for periampullary malignancy between June 2004 and June 2010 at a tertiary hospital (Austin Health, Melbourne, Australia) were identified from a prospectively maintained surgical and endoscopic database with institutional review board approval. A 
retrospective review of charts was undertaken to obtain specific information not available from the database. Cross checks were made between hospital records, pathology reports, and imaging results to exclude cases of hilar and intra-hepatic cholangiocarcinoma and clearly nonmalignant lesions. Only patients with cancers of the pancreatic head/uncinate process, distal bile duct, and ampulla of Vater and surrounding duodenum were included.

Patients were considered to be in the stent group if the primary mode of intervention was biliary stent insertion for palliation. Patients were considered to be in the surgical bypass group if biliary bypass was performed, usually in combination with gastric bypass as the primary mode of palliation. Many patients in the surgical group had temporary biliary stents prior to definitive surgical intervention.

In medically fit patients with locally unresectable or metastatic disease on imaging, the decision to perform metallic stent insertion or surgical bypass was determined by the treating physician, based on the perceived benefit of one procedure over the other.

\section{Pre-procedural assessment data}

Demographic data including, age, sex, American Society of Anesthesiologists (ASA) classification, main symptom at presentation, laboratory findings, and reason for palliation were abstracted for each patient. The time of initial diagnosis was considered the time when an intervention was first undertaken to obtain tissue diagnosis, whether endoscopic or at time of surgery.

\section{Outcome and follow up}

The type and number of various interventions performed were abstracted. In patients treated by metal stent insertion, the time between first metal stent insertion and any subsequent stent insertion or operation for a stent complication was noted. A post-procedural complication was considered any event that required an intervention such as operation, biliary or duodenal stent insertion, drainage, or antibiotics. Metal stent patency was similarly determined and compared as for survival, with stent occlusion defined as the timeframe from initial metal stent insertion to stent failure, upon which further stent insertion or operative procedures were required. Expandable uncovered metal stents were used for biliary stenting, with no patient treated by covered metal stents. Uncovered Wallfex ${ }^{\circledR}$ (Boston Scientific, Natick MA, USA) and Zilver stents (Cook Medical, Brisbane, QLD, Australia) were used in this series

In the surgical bypass treated group, the preferred biliary reconstruction technique was a retrocolic end to side hepaticojejunostomy with a Roux-en-Y reconstruction. A retrocolic 
gastrojejunostomy onto a loop of proximal jejunum was the preferred gastric bypass technique.

Complete follow up was achieved through review of hospital, primary physician, and medical records.

\section{Statistical analysis}

Results are expressed as median (range) unless otherwise stated. Comparisons between categorical variables were determined by chi-square or Fisher's exact test, where appropriate. Noncategorical variables were assessed by Mann-Whitney U test. Survival analysis was performed by the Kaplan-Meier product-limit method to determine overall survival after initial diagnosis. Comparisons between survival curves were made by log-rank test. Cox proportional analysis was undertaken to determine factors independently associated with survival using all factors where $p<0.1$ on univariate analysis. A statistical software package (SPSS Version 16.5, Chicago, IL, USA) was used for statistical analysis, with $p \leq$ 0.05 considered statistically significant.

\section{Results}

A total of 69 patients were included in this study (Table 1). Biliary and gastric bypass was performed as the primary mode of palliation in 28 patients. Twenty-one of these patients were offered potentially curative pancreaticoduodenectomy but were found to have an inoperable locally advanced disease or metastases at the time of abdominal exploration and underwent surgical bypass. Forty-one patients had biliary stent insertion as the primary mode of palliation, of which 39 (95\%) had metal stent placement.

\section{Patient characteristics}

Table 2 lists the characteristics of the patients in each group. Patients in the stent insertion group were older (74 [48-94] years) vs. 68 years (51-84 years); $p=0.014$ ), were more likely to present with jaundice as the main presenting symptom $(p=0.052)$, and were more likely to be palliated based on perceived poor fitness $(p=0.001)$. Differences in bilirubin level, platelet count, alkaline phosphatase (ALP), and alanine aminotransferase (ALT) were also noted between the two groups. In the surgical bypass cohort, 9 of 28 (32\%) patients were not clinically jaundiced (bilirubin $<50 \mu \mathrm{mol} / \mathrm{L}$ ) at presentation, compared to 4 of $41(10 \%)$ in the stent treatment group. There were no major differences in pathologic diagnosis between the groups $(p=0.368)$. Pancreatic cancer was the predominant pathology treated. Patients treated by stent insertion were less likely to receive chemotherapy in this series than those treated by surgical bypass (46 vs. $71 \% ; p=0.027$ ).

\section{Complications}


Complications were noted in both treatment groups (Table 3). One in-hospital death was noted in the stent group. This occurred in a patient with advanced cancer, where a decision was made to palliate the patient shortly after stent placement. Overall, there were significantly more complications in the stent insertion group than the surgical bypass arm (85 versus $36 \%$; $p=0.003)$. Stent occlusion or cholangitis following initial stent insertion occurred in $51 \%$ ( 21 of 41 ) of patients in the stent insertion group. Five cases had stent occlusion without clinical cholangitis. Four of the patients with cholangitis did not have clear stent occlusion. There was however no deaths directly attributed to cholangitis in these patients. Cholangitis was not observed in the surgical bypass group. Bacteria were isolated from blood cultures in 8 of 16 patients with cholangitis. Escherichia coli was the organism cultured in 5 of $8(63 \%)$ patients with positive blood cultures.

Most cases of stent occlusion were managed in a semi-elective manner, without the need for urgent hospital admission. Of the 21 patients with stent occlusion or cholangitis, only one required surgical biliary bypass. The remaining 20 patients had repeat stenting procedures. A median of 2(1-6) additional stenting procedures were required in these patients. In four of the cases plastic stent insertion was inserted for suspected cholangitis, but there was no clear occlusion. In two cases, plastic stents were used to manage stent to management stent occlusion alone. In 14 remaining cases further metal stent insertions were undertaken.

Five (13\%) patients in the stent group required subsequent surgery (Table 4). Four operations were required for duodenal obstruction and one other for recurrent biliary stent complications. These cases of duodenal obstruction were not considered amenable to stenting because of their location. One additional patient with duodenal obstruction was managed by duodenal metal stent insertion without stent occlusion. No revision operations were required in the surgical bypass group.

\section{Survival outcomes}

The overall 12 and 24 month survival in this series was $33 \%$ and $5 \%$, respectively. There was no significant difference between survival in the stent insertion group compared with surgical bypass group at 12 months ( 35 vs. $31 \%$ ) or at 24 months ( 4 vs. $8 \% ; p=0.57$ ) (Fig. 1). In the stent insertion group, the 23 of 41 patients with unresectable or metastatic disease were analyzed and the survival at 12 and 24 months was $23 \%$ and $0 \%$, respectively. This was however not statistically different to the surgical bypass group, in which all had unresectable or metastatic disease $(p=0.51)$. In the remaining 18 patients in the stent group with potentially resectable cancers, the 12 and 24 month survival was $50 \%$ and $9 \%$, 
respectively. This was however still not significantly different to the surgical bypass group $(p=0.51)$ There was also no statistically significant difference when the group of patients with resectable tumors were compared with metastatic or unresectable tumors in the stent group $(p=0.198)$.

Factors potentially influencing survival were examined (Table 5). Univariate analysis demonstrated a trend toward shorter survival in male patients $(p=0.06)$ and those with metastatic disease at presentation $(p=0.09)$. Patients with pain as the major presenting symptom appeared to have improved survival $(p=0.01)$. Multivariate analysis showed that pain remained a predictor for improved survival $(p=0.001)$ and metastatic disease was associated with poorer survival $(p=0.01)$.

\section{Stent patency}

In the 39 patients in this study who had metal stent insertion of the bile duct for palliation, stent occlusion was noted in $16(41 \%)$ patients following metal stent insertion. These appeared to be the result of a combination of tumor in growth and build-up of stent debris. The median stent patency was 224 days (Fig. 2). Stent patency was not significantly influenced by any of the various factors analyzed (Table 6). Furthermore, no trends were identified. Of these 16 patients, one had subsequent surgical biliary bypass. Fourteen of the remaining 15 had subsequent further metal stent insertions.

Two patients were managed with plastic stents alone. In one case a plastic stent was placed and the patient was palliated shortly thereafter. In another the patient, repeat plastic stenting was done on five occasions. The patient had a malignant appearing lesion that could not be confirmed on brushings and refused metal stent insertion. The patient eventually developed duodenal obstruction and was palliated.

\section{Discussion}

Periampullary malignancy, consisting of cancers of the pancreatic head/uncinate process, distal bile duct, and ampulla of Vater and surrounding duodenum, is associated with an extremely poor prognosis. The majority of patients are unsuitable for resection at presentation and the best form of palliation is not defined. The median survival based on current data for patients with periampullary malignancy ranges from 4 to 13 months [2]. Traditionally it was thought that surgical bypass may provide more long-lasting palliation [911]. Recovery from surgery may at times delay subsequent chemotherapy [2, 7]. Palliative biliary stent insertion in the era of newer stent technology may potentially provide similar effective palliation to that of surgical bypass. There are however few modern series that compare the two techniques $[4,7]$. 
The median survival in this series was 7 months. The overall survival rates in each group were similar. Similar survival rates have been reported in other series [2, 7]. The similarities in survival between groups were not anticipated, given that the stent insertion group contained older patients, many of who were perceived to have poorer general fitness. Patients in the stent group were also more likely to be jaundiced at presentation than those in the surgical group. There was however no suggestion that this equated to more advanced disease. Significantly fewer patients in the stent insertion group received chemotherapy. When patients with potentially resectable tumors were excluded from the stent group the survival times decreased, but the survival was still not significantly different from the surgical group. Survival of patients with resectable tumors in the stent group was not significantly different from patients treated by surgery. Metastasis was the only independent predictor of poor survival. This has been reported in other series [8, 12]. Of interest, pain at presentation was independently associated with improved survival. The reason for this is unknown. One speculation may be that these patients presented earlier in the course of disease, with an apparent improved survival.

Biliary stent insertion, while an effective method of palliation and providing equivalent survival to surgical bypass, was associated with significant complications. In patients with metal stent insertion the medial stent patency was 224 days. This compares to other studies that quote a stent patency rate of between 108 and 319 days [5, 13, 14]. The stents utilized in our series were all uncovered. It appears that the use of covered or uncovered stents does not result in clinically significant differences in stent patency [13-15]. Close to half of patients in our series required repeat stent insertions for occlusion after metallic biliary stent insertion. Repeat metal stenting was performed in 14 of 16 cases of metal stent occlusion. There was however no mortality associated specifically with cholangitis in this series. When various factors that may influence stent patency were examined, no significant difference was identified. This suggests that stent patency is largely related to survival time, with occlusion becoming more likely with increasing survival.

The requirement for surgical intervention in the stent-only group was significant. Gastric outlet obstruction was encountered in 5 of $39(13 \%)$ patients. One was treated with duodenal stent insertion, with the remaining by open gastrojejunostomy. In the surgical group no revisional surgery was required. Duodenal stent insertion has been shown in several series to be effective in the management of gastric outlet obstruction [5, 16]. This can however be technically difficult, particularly if the obstruction is in the third or fourth part of the duodenum. Only one of our cases was considered suitable for duodenal stent insertion. 
There are increasing reports of laparoscopic bypass as an effective method of surgical palliation [3, 4]. A comparative study undertaken demonstrated the superiority of laparoscopic palliative bypass over the traditional open procedure. Improvements in mortality, morbidity, and complication rate were observed. No significant differences were observed between the stent insertion and laparoscopic groups, excluding procedural costs.

The limitations of a retrospective study with small numbers are acknowledged. Follow up in this study was however complete and statistical differences were identified. Given that the majority of patients undergoing surgery did so with initial intent of surgical resection, a randomized trial to compare open surgical bypass versus metallic stent insertions would be difficult. Large numbers of patients with either locally unresectable or low volume metastatic disease, medically fit for either surgery or stenting, would be required for randomization. It is unlikely for any one center to be able to undertake such a study. Currently, inferences regarding the benefits of metal stenting versus surgical bypass are made from retrospective studies such as this.

\section{Conclusion}

The choice of palliation for periampullary cancer is important. Stent insertion has no survival disadvantages to surgical bypass. In patients who are likely to survive beyond 9-12 months, biliary metal stent insertion is unlikely to produce palliation without the need for repeat interventions. Stent-related complications such as cholangitis and occlusion are likely to occur with prolonged survival, requiring repeat procedures and may significantly impair the quality of life. Surgical bypass appears to provide good long-term palliation without significant late complications.

Acknowledgments: The authors acknowledge the contribution of Mr Vin Surendran for developing and maintaining a prospective surgical database that was accessed for this study.

Fig. 1 Kaplan-Meir survival curve of patients with periampullary malignancy palliated by biliary stent insertion or surgical bypass. Comparison by using log-rank method 


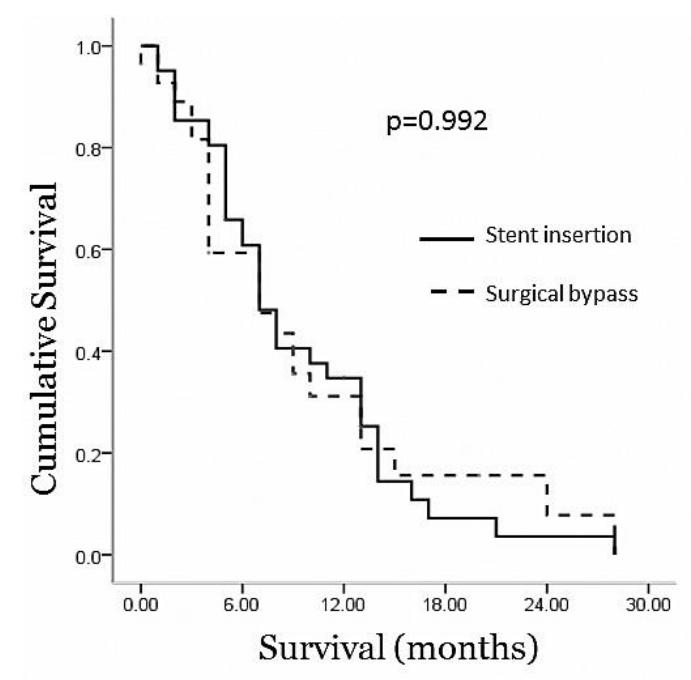

Fig. 2 Stent patency times of patients with periampullary malignancy treated by metal stent insertion. Kaplan-Meir limit method

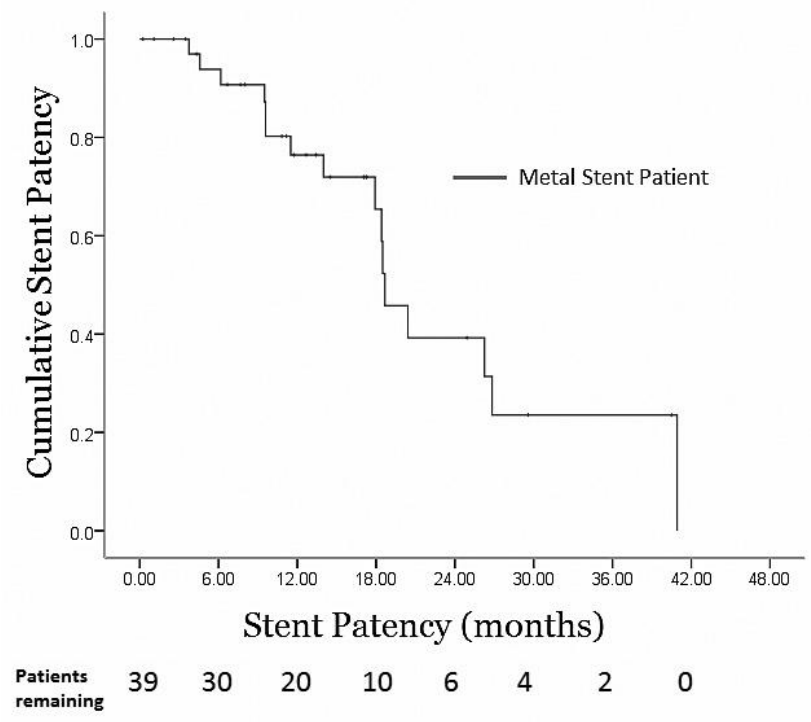

\section{References}

1. Sohn TA, Yeo CJ, Cameron JL, et al. Resected adenocarcinoma of the pancreas-616 patients: results, outcomes, and prognostic indicators. J Gastrointest Surg. 2000;4:56779.

2. Mukherjee $S$, Kocher HM, Hutchins RR, et al. Palliative surgical bypass for pancreatic and peri-ampullary cancers. J Gastrointest Cancer. 2007;38:102-7.

3. Rhodes M, Nathanson L, Fielding G. Laparoscopic biliary and gastric bypass: a useful adjunct in the treatment of carcinoma of the pancreas. Gut. 1995;36:778-80.

4. Siddiqui A, Spechler SJ, Huerta S. Surgical bypass versus endoscopic stenting for malignant gastroduodenal obstruction: a decision analysis. Dig Dis Sci. 2007;52:276-81. 
5. Akinci D, Akhan O, Ozkan F, et al. Palliation of malignant biliary and duodenal obstruction with combined metallic stenting. Cardiovasc Intervent Radiol. 2007;30:1173-7.

6. Mann CD, Thomasset SC, Johnson NA, et al. Combined biliary and gastric bypass procedures as effective palliation for unresectable malignant disease. ANZ J Surg. 2009;79:471-5.

7. Maosheng D, Ohtsuka T, Ohuchida J, et al. Surgical bypass versus metallic stent for unresectable pancreatic cancer. J Hepatobiliary Pancreat Surg. 2001;8:367-73.

8. Nuzzo G, Clemente G, Cadeddu F, et al. Palliation of unresectable periampullary neoplasms. "Surgical" versus "non-surgical" approach. Hepatogastroenterology. 2004;51:1282-5.

9. Taylor MC, McLeod RS, Langer B. Biliary stenting versus bypass surgery for the palliation of malignant distal bile duct obstruction: a meta-analysis. Liver Transpl. 2000;6:302-8.

10. Wong YT, Brams DM, Munson L, et al. Gastric outlet obstruction secondary to pancreatic cancer: surgical vs endoscopic palliation. Surg Endosc. 2002;16:310-12.

11. Smith AC, Dowsett JF, Russal RCG. Randomised trial of endoscopic stenting versus surgical bypass in malignant low bile duct obstruction. Lancet. 1994;344:1655-60.

12. Tani M, Kawai M, Hirono S, et al. A pancreaticoduodenectomy is acceptable for periampullary tumors in the elderly, even in patients over 80 years of age. J Hepatobil Pancr Surg. 2009; 16:675-80.

13. Yoon WJ, Lee JK, Lee KH, et al. A comparison of covered and uncovered Wallstents for the management of distal malignant biliary obstruction. Gastrointest Endosc. 2006;63:996-1000.

14. Soderlund C, Linder S. Covered metal versus plastic stents for malignant common bile duct stenosis: a prospective, randomized, controlled trial. Gastrointest Endosc. 2006;63:986-95.

15. Mumtaz K, Hamid S, Jafri W. Endoscopic retrograde cholangiopancreaticography with or without stenting in patients with pancreaticobiliary malignancy, prior to surgery. Cochr Collaboration 2009;

16. Gaidos JK, Draganov PV. Treatment of malignant gastric outlet obstruction with endoscopically placed self-expandable metal stents. World J Gastroenterol. 2009;15:436571. 
Table 1 Surgical bypass or primary stenting for treatment of periampullary malignancy (2004-2010)

\begin{tabular}{lc}
\hline Patient cohort & Patients (\%) \\
\hline Surgery (bypass) & $28(41)$ \\
Stent (metallic/polyethelene) & $41(59)$ \\
\hline Overall & 69 \\
\hline
\end{tabular}

Table 2 Demographic factors

\begin{tabular}{|c|c|c|c|c|}
\hline & $\begin{array}{l}\text { Overall } \\
(n=69)\end{array}$ & $\begin{array}{c}\text { Stent (any) } \\
(n=41)\end{array}$ & $\begin{array}{c}\text { Surgical bypass } \\
\qquad(n=28)\end{array}$ & $\begin{array}{l}\text { Difference, } p \text { - } \\
\text { value }\end{array}$ \\
\hline \multicolumn{5}{|l|}{ Characteristics } \\
\hline Male & $40(58.0)$ & $23(56)$ & $17(61)$ & 0.806 \\
\hline Age, median years & 72 (48-94) & $74(48-94)$ & $68(51-84)$ & $0.014 *$ \\
\hline ASA & & & & 0.116 \\
\hline II & $11(16)$ & $4(10)$ & $7(25)$ & \\
\hline III & 37 (54) & $22(54)$ & $15(54)$ & \\
\hline IV & $20(29)$ & $15(37)$ & $5(18)$ & \\
\hline V & $1(1)$ & $0(0)$ & $1(4)$ & \\
\hline Major symptom & & & & $0.052^{*}$ \\
\hline Jaundice & $49(71)$ & $32(78)$ & $17(61)$ & \\
\hline Pain & $5(7)$ & $1(2)$ & $4(14)$ & \\
\hline Nausea/vomiting & $7(10)$ & $2(5.0)$ & $5(18)$ & \\
\hline Other & $8(12)$ & $6(15)$ & $2(7)$ & \\
\hline Reason for noncurative treatment & & & & $0.001 *$ \\
\hline Metastasis & $29(42)$ & $16(39)$ & $13(46)$ & \\
\hline Poor Fitness & $11(16)$ & $11(27)$ & $0(0)$ & \\
\hline Unresectable & $22(32)$ & $7(17)$ & $15(54)$ & \\
\hline Age & $2(3)$ & $2(5)$ & $0(0)$ & \\
\hline Other & $5(7)$ & $5(12)$ & $0(0)$ & \\
\hline \multicolumn{5}{|l|}{ Pathology } \\
\hline Presence of metastases & $38(55)$ & $22(54)$ & $16(57)$ & 0.810 \\
\hline Locally advanced tumor & $54(78)$ & $29(71)$ & $25(89)$ & 0.067 \\
\hline Postprocedure chemotherapy & $39(57)$ & $19(46)$ & $20(71)$ & $0.027^{*}$ \\
\hline Tumor origin & & & & 0.368 \\
\hline Pancreatic & $58(84)$ & $34(83)$ & $24(86)$ & \\
\hline Cholangiocarcinoma & $6(9)$ & $5(12)$ & $1(4)$ & \\
\hline Ampullary/duodenal & $5(7)$ & $2(5)$ & $3(11)$ & \\
\hline \multicolumn{5}{|l|}{ Laboratory tests } \\
\hline Hemoblobin, g/l & 118 (77-157) & $119(85-157)$ & $116(77-151)$ & 0.779 \\
\hline WCC, k/ul & $8.0(4.1-20.1)$ & $7.5(4.8-16.4)$ & $8.7(4.1-20.1)$ & 0.213 \\
\hline Platelets, k/ul & $252(82-806)$ & $243(82-806)$ & $321(116-665)$ & $0.021 *$ \\
\hline Bilirubin, $\mu \mathrm{mol} / \mathrm{l}$ & $166(7-594)$ & $190(9-594)$ & $110(7-392)$ & $0.030 *$ \\
\hline Albumin, g/dl & $27(15-43)$ & $27(16-40)$ & $28(15-43)$ & 0.489 \\
\hline ALP (U/L) & 391 (39-1747) & $593(72-1747)$ & 277 (39-1260) & $0.020^{*}$ \\
\hline ALT (U/L) & $190(11-2331)$ & $198(18-2331)$ & $140(11-434)$ & $0.046^{*}$ \\
\hline GGT (IU/L) & $533(8-1815)$ & $570(84-1496)$ & $310(8-1815)$ & 0.093 \\
\hline $\mathrm{CRP}(\mathrm{mg} / \mathrm{l})$ & $16(1-379)$ & $26(1-281)$ & $13(1-379)$ & 0.434 \\
\hline
\end{tabular}

ASA American Society of Anesthesiologists, WCC white cell count, ALP alkaline phosphatase, ALT alanine transaminase, GGT gamma glutamyl transpeptidase, CRP C-reactive protein Missing: $C R P(n=18)$

$* p \leq 0.05$ 


\begin{tabular}{|c|c|c|c|}
\hline & $\begin{array}{l}\text { Biliary stent } \\
n=41(\%)\end{array}$ & $\begin{array}{c}\text { Surgical } \\
\text { bypass } n=28 \\
(\%)\end{array}$ & $\begin{array}{l}\text { Difference, } \\
p \text {-value }\end{array}$ \\
\hline Overall complications & $35(85)$ & $10(36)$ & $0.003^{*}$ \\
\hline Deaths & $1(2)$ & 0 & $\mathrm{~N} / \mathrm{S}$ \\
\hline \multicolumn{4}{|l|}{ Postoperative complication } \\
\hline Failed endoscopic stenting & $4(10)$ & N/A & $\mathrm{N} / \mathrm{A}$ \\
\hline Bile duct injury & $1(3)$ & $N / A$ & N/A \\
\hline Pancreatitis & $3(7)$ & $1(4)$ & $\mathrm{N} / \mathrm{S}$ \\
\hline Wound infection & $N / A$ & $3(11)$ & $\mathrm{N} / \mathrm{A}$ \\
\hline Sepsis & N/A & $1(4)$ & $\mathrm{N} / \mathrm{A}$ \\
\hline STEMI/NSTEMI & N/A & $2(7)$ & $\mathrm{N} / \mathrm{A}$ \\
\hline Hemorrhage & N/A & $1(4)$ & $\mathrm{N} / \mathrm{A}$ \\
\hline \multicolumn{4}{|l|}{ Postdischarge complication } \\
\hline Stent occlusion or cholangitis & $21(51)$ & N/A & N/A \\
\hline Cholangitis & $16(39)$ & $0(0)$ & $<0.001$ \\
\hline Duodenal obstruction & $4(10)$ & $0(0)$ & $0.012 *$ \\
\hline DVT & $1(2)$ & $1(4)$ & $\mathrm{N} / \mathrm{S}$ \\
\hline Other & $1(2)$ & $1(4)$ & $\mathrm{N} / \mathrm{S}$ \\
\hline \multicolumn{4}{|l|}{ Outcomes } \\
\hline $\begin{array}{l}\text { Re-admission within 12-month } \\
\text { (emergency) }\end{array}$ & $12(29)$ & $5(18)$ & $\mathrm{N} / \mathrm{S}$ \\
\hline $\begin{array}{l}\text { Requirement for surgery (post } \\
\text { procedure) }\end{array}$ & $5(13)$ & $0(0)$ & $0.012^{*}$ \\
\hline Gastrojejunostomy & $4(10)$ & N/A & N/A \\
\hline $\begin{array}{l}\text { Hepaticojejunostomy and } \\
\text { gastro-enterostomy }\end{array}$ & $1(3)$ & N/A & $\mathrm{N} / \mathrm{A}$ \\
\hline $\begin{array}{l}\text { STEMI ST-elevation myocardial infarction, } D V \\
\text { (stent); renal failure (surgery); } N / S \text { non-signifi } \\
{ }^{*} p \leq 0.05 \text {. }\end{array}$ & nous thromb & & \\
\hline
\end{tabular}

Table 4 Type of surgical intervention for treatment of complications in metallic stent treated group $(n=39)$

\begin{tabular}{lccc}
\hline \multicolumn{1}{c}{ Surgery } & Number & Complication & $\begin{array}{c}\text { Median time after metallic } \\
\text { biliary stent insertion (days) }\end{array}$ \\
\hline $\begin{array}{l}\text { Gastrojejunostomy } \\
\begin{array}{l}\text { Hepaticojejunostomy } \\
\text { and } \\
\text { gastrojejunostomy }\end{array}\end{array}$ & 4 & Duodenal obstruction & 61 \\
\hline
\end{tabular}

Table 5 Predictors of overall survival in patients palliated with periampullary malignancy

\begin{tabular}{llcccc}
\hline & $\begin{array}{c}\text { 12-month } \\
\text { survival }(\%)\end{array}$ & $\begin{array}{c}\text { 24-month } \\
\text { survival }(\%)\end{array}$ & $\begin{array}{c}\text { Univariate analysis } \\
(\log \text { rank test })(p)\end{array}$ & $\begin{array}{c}\text { Multivariate analysis (cox } \\
\text { proportional hazard } \\
\text { regression) }(p)\end{array}$ \\
\hline Sex & & & & \\
& Male & 24 & 4 & 0.06 & 0.303 \\
& Female & 46 & 7 & &
\end{tabular}


Age (years)

$$
\begin{aligned}
& \geq 70 \\
& <70
\end{aligned}
$$

Major symptom

Jaundice

28

Not jaundiced

44

Pain

67

No pain

28

Hemoglobin $(\mathrm{g} / \mathrm{L})$

$<100$

33

$\geq 100$

29

0.81

WCC (k/ul)

$\geq 10$

31

$<10$

33

0.15

Albumin (g/dL)

$<25$

$\geq 25$

33

36

0.38

Bilirubin $(\mu \mathrm{mol} / \mathrm{L})$

$\geq 200$

$<200$

28

37

0.57

Metastatic disease

Yes

No

Origin of tumor

Pancreatic

Cholangiocarcinoma

Ampullary/duodenal

0

N/A

Locally advanced

Yes

No

Chemotherapy

Yes

No

Complication

Yes

No

Procedure

Stent (any type)

Bypass

Metal stent

45

21

35

31

Yes

No

Overall survival

4
7 
Table 6 Specific factors contributory to metal stent patency

\begin{tabular}{|c|c|c|c|}
\hline & $\begin{array}{c}\text { Occlusion } n(\%) \\
(n=16)\end{array}$ & $\begin{array}{l}\text { Nil Occlusion } n(\%) \\
(n=23)\end{array}$ & $\begin{array}{c}\text { Difference, } \\
p \text {-value }\end{array}$ \\
\hline Sex & & & 0.31 \\
\hline Male & $6(38)$ & $15(65)$ & \\
\hline Female & $10(63)$ & $8(35)$ & \\
\hline Age (years) & & & 0.29 \\
\hline$\geq 70$ & $11(69)$ & $19(83)$ & \\
\hline$<70$ & $5(31)$ & $4(17)$ & \\
\hline ASA & & & 0.18 \\
\hline II & $3(19)$ & $1(4)$ & \\
\hline III & $9(56)$ & $12(52)$ & \\
\hline $\mathrm{IV} / \mathrm{V}$ & $4(25)$ & $10(44)$ & \\
\hline Presence of metastases & & & 0.42 \\
\hline Yes & $5(31)$ & $15(65)$ & \\
\hline No & $11(69)$ & $8(35)$ & \\
\hline Pathology & & & 0.13 \\
\hline Pancreatic carcinoma & $12(75)$ & $20(87)$ & \\
\hline Cholangiocarcinoma & $3(19)$ & $2(10)$ & \\
\hline Ampullary/duodenal cancer & $1(6)$ & $1(4)$ & \\
\hline Chemotherapy & & & 0.40 \\
\hline Yes & $8(50)$ & $10(44)$ & \\
\hline No & $8(50)$ & $13(57)$ & \\
\hline
\end{tabular}

